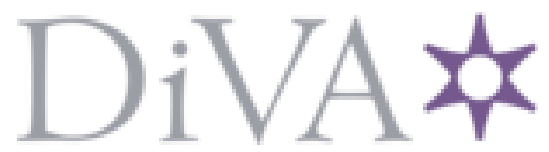

http://www.diva-portal.org

\title{
Postprint
}

This is the accepted version of a paper published in New Media and Society. This paper has been peerreviewed but does not include the final publisher proof-corrections or journal pagination.

Citation for the original published paper (version of record):

Kaun, A., Stiernstedt, F. (2014)

Facebook time: Technological and institutional affordances for media memories.

New Media and Society, 16(7): 1154-1168

https://doi.org/10.1177/1461444814544001

Access to the published version may require subscription.

N.B. When citing this work, cite the original published paper.

Permanent link to this version:

http://urn.kb.se/resolve?urn=urn:nbn:se:sh:diva-24329 


\section{Facebook Time}




\begin{abstract}
People are spending increasingly more time on social media platforms, with Facebook being the biggest and most successful. Historically, media technologies have for long been considered of importance for the structuration and the experience of time in general. In this article, we investigate the technological affordances of Facebook for the temporal experiences of its users. Relying on a case study of a Facebook page dedicated to media memories, we link user experiences to technological and institutional affordances. By doing so, we seek to answer the question of how a business model and an infrastructure that largely build on immediacy and newness are experienced and negotiated by users that engage in a multiplicity of durations and time layers in their everyday lives. Drawing on a platform analysis, in-depth interviews and a survey among the users of the page "DT64 - das Jugendradio der DDR”, we develop the concept of "social media time" while considering notions of the archive, flow, and narrative, which contribute to shedding light on how specific media technologies afford specific temporalities. Then we discuss the consequences for the users and society at large.
\end{abstract}

\title{
Keywords
}

Facebook; time; temporality; memory; platform analysis; institutional affordances;

technological affordances, user experiences, media memories 


\section{Facebook Time}

People are spending more and more time on social media platforms. Among these social media platforms, Facebook is currently the most successful. A recent Business Insider Report states that a total of 114 billion minutes a month are spent on Facebook in the United States alone, beating all other social networking sites ${ }^{1}$ (see also Fuchs, 2014). Users not only spend time on Facebook, which can now be tracked with the help of an application, ${ }^{2}$ Facebook also organizes its users' time in terms of managing social contacts, reminding us of birthdays and events, and serving as an archival repository, providing access to past memories. The purpose of this article is to analyze how Facebook (re-)structures the experience of temporality in conjunction with its technological affordances for doing so.

In this article, we link the theoretical aspects of earlier research on media-related changes of time-space configurations and engage with current discussions on online social media in relation to time and memory. While earlier studies of users' experiences have discussed Facebook as offering new strategies in terms of self-care (Sauter, 2013), identity formation (boyd, 2012), and memory work (Garde-Hansen, 2009; Lessard, 2009; Zhao et al., 2013), the temporal aspects and experiences have, to our knowledge, not yet been considered extensively (Caers et al., 2013; Leong, Mitew, Celletti, \& Pearson, 2009). Building on and expanding earlier studies, we suggest social media time as a framework for analyzing the specific way in which the Facebook platform structures temporal experiences.

Linking the analysis of technological affordances of social media time with experiences, we asked how users navigate, make sense of, and problematize the possibilities and constraints concerning the structuration of time within the platform. In the analysis, we conceptualize the answers by showing the relation between the platform and three different

\footnotetext{
${ }^{1}$ Business Insider Report http://www.businessinsider.com/social-media-engagement-statistics-201312\#ixzz2rung9ktO, accessed February 25, 2014.

2 http://techland.time.com/2014/01/27/how-much-time-have-you-wasted-on-facebook/, accessed February 25, 2014.
} 
notions (of time): archive, flow, and narrative. Consequently, the analysis is concerned with both the implicit and the explicit forms of taking part in the platform and its temporal structuration. The implicit participation referring to the inscribed way of usage that is designed by the engineers and the implemented coding mechanisms, while the explicit participation refers to the way users interact with the platform (van Dijck, 2013; van Dijck \& Poell, 2013). A fundamental starting point of the analysis is, hence, that we consider platforms as structured and structuring rather than as neutrally lending themselves to all kinds of usages (Gillespie, 2010).

To explore these questions empirically, we have analyzed the platform affordances of Facebook in the context of one specific fan page dedicated to media memories being defined as memories of media technologies, texts, and institutions (Authors 2012). The case that we are discussing is the page "DT64 - Das Jugendradio der DDR," which is dedicated to an East German youth radio station that operated between 1964 and 1993. The analysis focuses on the page's organization of different layers of temporality that are consequently translated for the platform as such.

\section{Time and the Media}

In the following, we discuss historical conceptions of time as a social construct to then ask for the importance of media technologies, Facebook being one of which, for temporal experiences.

John Urry (2002) distinguished conceptions of time into different periods. He started with the pre-twentieth-century understanding of time as being absolute, invariant, and infinitely divisible into units. The understanding of time evolved around its measurability and expression in numbers. This perception changed during the twentieth century. Time was now seen as internal to the relationship between objects rather than external. Time and space he considered as being part of the processes that constitutes the social world rather than as 
extrinsic measures. Similarly, Susan Buck-Morss (1990) in her reading of Walter Benjamin suggested the distinction between two epochs of temporal experience. The first epoch evolved slowly over millions of years (deep time) while the second epoch, starting with the industrial revolution, she characterized by constant change that was closely linked to technologies.

Paramount to a shift in how time is conceptualized, Henri Bergson (1960) suggested the notion of duration in his doctoral thesis “Time and Free Will,” which was first published in 1889. He proposed duration as a critique of the attempt to fix time through the scientific measurement that was prevalent in modern conceptions of time. He posited that duration, in contrast, should be understood as never fixed, continuously changing and always incomplete. This position opened up the ability to conceptualize time as multiple and hybrid in nature, which idea is at the heart of the analysis here, as we asked how Facebook affordances potentially re-structure this configuration of temporality or duration as multitude. While assuming the multi-layeredness of temporality, we engaged with the idea of the disappearance of duration or the end of temporality as proposed by Fredric Jameson (2003) and Jonathan Crary (2013). Jameson (2003) argued that "postmodern generations are dispossessed (without even knowing it) of any differential sense of that deep time that the first moderns sought to inscribe in their writing” (p. 699). Similarly, other scholars have suggested that technologies for structuring time and experiencing temporality are connected to the general mode of production in society. As John Durham Peters (2013) pointed out, calendars and clocks are central media technologies for creating and maintaining the temporal regimes of modern society.

Media technologies are, hence, in a profound way about organizing and creating a sense of time. As the French philosopher Henri Lefebvre (2004) argued in Rhythmanalysis, “The media occupies days. It makes them. It speaks of them.... Can you imagine this flow that covers the globe, not excluding the oceans and deserts? It has a meaning: time” (p. 46). 
Different media hold different possibilities regarding how they can construct and (re-)produce temporality (Keightley, 2013). At the same time, socio-cultural constructs of temporality are interrelated with our means of communication, with our media technologies and forms. Media technologies such as the private camera, the diary, and the calendar have long been used to keep track of time and help people remember things. Television and radio created a new era of simultaneity tied to the formation of the collective memory of societies. Through recurring live broadcasts of festivities and holidays (i.e. The Queen's Speech, The State of the Union, the Super Bowl), the division of the year into television seasons and the structuring of the day through specific programs at specific times, television has held an important role in creating what Paddy Scannell (2014) has called “common public time” (p. 365). With the computer, the structuring of time and the mnemonic functions of media became digital, with the Internet networked and with social networking sites they have become social, providing what Andrew Hoskins (2009) called “social network memory” (p. 30). It is, as Hoskins (2009) noted, not so much that events (memory, history, time) are straightforwardly mediated by media to audiences; instead media have entered into the production of events to such an unprecedented extent that those events should be considered mediatized. Consequently, social media in many respects, at least potentially, transform our possibilities for experiencing temporality and engaging with the past, present, and future (Garde-Hansen, Hoskins \& Reading, 2009). Hoskins (2009) aimed to tackle media-related changes in social relations that have long been of scholarly interest. One aspect of this inquiry has been the changing relationship of time and space through media technologies (Harvey, 1990; Meyrowitz, 1985). Emily Keightley (2012) referred, for example, to Anthony Giddens and his discussion of time-space distanciation, namely that our experience of time is delinked from space. Giddens (1994) argued furthermore that the change of time and space constellation is not related to content but to the reproducible structure and characteristics of the medium as a carrier. 


\section{Social Media Time}

Fuchs (2014) proposed that social media, in various ways, order and structure time to accumulate economic surplus value. The temporal affordances of Facebook could hence be related to the mode of production that this platform represents. The business model of social network media is built on commercial surveillance: Social network media are "profiling machines” (Elmer, 2003) that collect and process data in order to sell the knowledge about users to advertisers (Andrejevic, 2013). Knowledge that is constituted by the communication performed, the content published, shared, and liked are gathered and exploited (Dean, 2008). Facebook's business model is crucially built around the dispossession of users' private photos, communication, networks of friends etc., under the guise of "networked production" or “networked sociality.” This dispossession has been interpreted as a parallel to the Marxist concept of "primitive accumulation," hence social network media is a means of moving things from the exterior to the interior of the capitalist economy. Communication and sociality that previously belonged to the "cultural commons" have been privatized via these platforms (Author, 2010). Hence, social network media represent an increased commodification of sociality and communication. As part of the regular capitalist economy, private communication and other leisure activities that take place on platforms such as Facebook can be understood as forms of labor. Against this background, Christian Fuchs (2014) among others has suggested that commercial platforms are claiming a monopoly on temporal experiences and temporal organization by offering a multiplicity of temporal layers with the ultimate aim of engaging the users for longer periods of time and more often. Growing scholarship on free labor, digital labor and “playbor” reflects this argument by proposing that the longer the hours of work or engagement, the greater the rate of exploitation and, thereby, profits (Fuchs, 2014; Fuchs \& Sevignani, 2013; Gershuny, 2002). Time is consequently restandardized as social media time, specified here as social media time. 
In the attempt to engage users longer and more often, Facebook rests on the principle of constant change and flow of newness that has been addressed by earlier studies as immediacy and “liveness” of social media (Bolter, MacIntyre, Nitsche, \& Farley, 2012; Gerlitz, 2012) the proposed re-standardization of time as social media time resonates with these studies that have pointed out the immediacy and speed characterizing social relations nowadays (Crow \& Heath, 2002; Davis, 2013) that are tightly linked to evolving media technologies, for example, as Keightley (2012) argued, the dominant framing of time is that it has become a property of media technologies, which is imposed on social relations.

In order to grasp the character of temporality fostered through technology, we analyze the affordances of Facebook. However, while considering the structuration of time through the logics of the platform Facebook, we also take the users' perception and negotiation of these suggested temporal layers into account. We examine the temporal logics and novel ways to forge connections between individual and social time in the platform in these areas.

\section{Entry Points}

We start our analysis with one Facebook page dedicated to a radio station that officially disappeared from the media landscape in the early 1990s: DT64, a youth radio station in the former German Democratic Republic (GDR). DT64 has remained present, however, through media memory practices, e.g. memories exercised in, through, and by the media, and it has a considerable and still-growing fan base with more than 7,000 likes on Facebook.

The starting point for the analysis are media memories, i.e. memories that not only involve media in memory practice or that have media representations as referential frames, but that are phenomena in their own right (Lagerkvist, 2012a; 2012b; Neiger, Meyers, \& Zandberg, 2011; van Dijck, 2007). Based on previous studies, we define media memories as people’s memories of media texts, media experiences, and practices related to a specific 
medium. The Facebook page dedicated to DT64 provides an ideal case study of media memory practices performed on a commercial platform integrating a multiplicity of temporal layers such as DT64 time, Facebook time, and user time. Consequently, we argue that analyzing a commemorative page offers multiple entry points to temporal affordances on the one hand, and temporal experiences on the other.

The methodological approach is hence slightly different from that of earlier studies of social networking platforms, which have attempted to broadly map content and user behavior (Lange, 2007; Marwick \& boyd, 2011; Rotman \& Preece, 2010) or focused on institutional affordances and the political economy of platforms (Cohen, 2008; Hyunjin \& McAllister, 2011).

The analysis builds on three major sources: an initial study including in-depth interviews and an analysis of the Facebook page identified fundamental nodes of analogue and digital media memories in the case of DT64, namely identity, alternativity, and temporality (Authors, 2012).

Based on this initial analysis, we developed a survey and extended the analysis of the page. The page analysis involved questions about the affordances of the site to perform media memories with a focus on temporal aspects while considering the actual user practices. For a basic quantitative page analysis, we used a free software tool calculating response rates to posts on the page and the intensity of exchanges among the users ${ }^{3}$. In addition to a platform analysis based on the content and the structuring of the Facebook page, we included the user experiences. For that purpose, we developed a survey that was posted on the page. The survey among the DT64 page users was supported by the page administrators. We and the administrators repeatedly promoted the survey and the call for participation. However, the

\footnotetext{
${ }^{3}$ For this purpose, we used Simply Measured's content analysis and page analysis tool calculating the user statistic for a two weeks period 22 August through 5 September 2013, http://simplymeasured.com/, accessed 11 September 2013.
} 
number of responses remained low, with only 27 respondents. ${ }^{4}$ We decided, therefore, to focus the analysis on the platform affordances and content while relying on the survey as contextualizing material.

In terms of the population, i.e. the users of the site, we only had access to data concerning the total number of current 7,135 followers (as of February 2014). For the first data collection that was conducted in December 2011, Facebook statistics of the site where still openly available giving more detailed information in terms of gender and location of the users.

From the survey, we found that regular users of the page who participated mainly found the page through actively searching for DT64 on Facebook (54 per cent), and others came across it because friends had liked the page (15 per cent). A majority of the surveyed participants engaged with the page several times a week or even on a daily base (taken together 18 respondents). In terms of the intensity of Facebook usage in general, these figures are quite high. Most of the participants logged onto their Facebook accounts several times a day (20 respondents, mainly for reading their newsfeed) and had a moderate number of friends (max. 500). In terms of security and privacy settings, the respondents considered themselves to be rather savvy. They kept themselves updated about changes in Facebook's terms of usage and had adjusted their privacy settings to their individual needs, i.e. granting only friends access to their pictures and posts. Some had separate friends' lists that distinguished between contacts in terms of access to pictures and content that they posted. In demographic terms, the participants in the survey reflected the target audience of DT64, people born in the 1960s and 1970s. Two of the participants were actually too young to have been former audience members. In terms of gender, more men were participating (17

\footnotetext{
${ }^{4}$ The response rate is 0.4 per cent considering all users who have liked the page (6,780 as of September 2013). Calculating the response rate in this way, however, is difficult as it is not certain how many of them have actually seen the call, as the algorithm Facebook uses determining the content that appears in the newsfeeds of the individual user is not fully known.
} 
respondents) compared to women (6 respondents). As indicated earlier, we were using the responses to illustrate general tendencies and are very cautious in extrapolating them for the whole group.

\section{Social Media Time Instead of Duration?}

The Facebook page DT64 as a whole can be considered a connective memory ecology ${ }^{5}$ offering possibilities to post, comment, share, and like memorabilia. However, the way in which users are connecting in the memory work is guided by technological infrastructure, which dialectically combines immediacy and durability, "liveness,” and storage in memory work. In the following section, we develop three notions to explain the specificity of Facebook time: archive, flow, and narrative.

\section{Archive}

The case of DT64 shows the importance of social media platforms in relation to issues of temporality and how such media platform can empower people to produce cultural histories. The radio station operated in East Germany between 1964 and 1993 and was closed shortly after the German reunification. DT64 that was one of the rare East German media outlets that provided popular Western music and was of great importance for many young citizens of the GDR (Lietz, Honeit, \& Rauhut, 2006; Stahl, 2010). The shut-down of the station resulted in street demonstrations and various other forms of protests and activism from its audience (Ulrich \& Wagner, 1993). Because DT64 was a part of the East German state media system, there is very poor documentation remaining of this once-prominent radio station. Very little, if any, materials were kept in official archives. Some books have been published by former employees of the radio station and one documentary film about DT64 exists, but with these exceptions the radio station is officially largely forgotten. Facebook could then possibly be of great importance in producing collective memories and writing

\footnotetext{
${ }^{5}$ Adapted from Jose van Dijck’s (2013) ecology of connective media.
} 
media history of DT64. Former fans and employees as well as ordinary listeners are potentially enable to contribute to a forum for sharing private memorabilia and their own archival material. For example, one of our interviewees told us about his collection of mix tapes that he recorded from DT64:

I still keep some mix tapes from before in the attic. I wasn’t really listening to them the last 5-6 years, but maybe I will in the future. Now with ITunes and so on, where you just can get everything and the fact that you don't have tape players any longer, not even in the car, you don’t really listen to tapes. But I will keep them all.

However, there are some problems for those who wish to use Facebook as an archive, problems which are aligned with the affordances of the platforms. The platform itself, and the company Facebook in particular, have the ambition to collect, store and process vast amounts of information and to act as giant archives. Facebook engineers have stated that "Facebook's data warehouses grow by 'over half a petabyte...every 24 hours”” (Facebook, 2012). These practices are, as we have discussed earlier, based on the specific business model of social network media. To use the platform as a personal archive, or as in the case of DT64, a site for collective memory work, is, however, not as straightforward. The technological structure of the platform allows only a few organizing principles, such as thematic “tagging,” or other methods for structuring content uploaded to the "stream.” Ordering and indexing, which are central elements for preserving data and for organizing temporality, are not well developed on the platform in general nor on the DT64-page. Lacking fundamental features to systematically archive uploaded materials, the Facebook page invites users to constantly upload new materials rather than to engage with older posts. This is enhanced by the fact that steady activity promotes the page’s visibility among users and potential users.

These affordances then, might at least partially explain why the DT64-page on Facebook has evolved into a forum for more general discussions of a nostalgic character, with 
many links to materials from general popular culture from the GDR, already circulating on, for example, YouTube.

Several shows broadcasted music with pauses before and after playing the songs in order to make recording easier. Other shows played entire albums from start to end with the intention that listeners could record them. This has resulted in the fact that many of the people engaged in the Facebook page, and the majority of our informants, have their own private archives of DT64 broadcasts. Even though the Facebook page is not directly used as an archive of recordings, the 'cassette culture' surrounding the radio station is often, and vividly, discussed on the page and fostered by posts from the page owners. Through social media platforms and through interconnecting various social media (in the case of the DT64 page, besides Facebook, also YouTube and SoundCloud) fans of DT64 can collaborate and create their own, individualized archives. One of the main motivations of doing so is to prevent DT64 from falling into oblivion, as another interviewee suggests:

The Facebook page is good to really build a memorial for the channel and so that it won’t be forgotten. But I didn’t make any new contacts there, unfortunately. There are not many people in my area that are interested in these kinds of things.

Even if only a few users contribute actively, one of the functions of the page is, thus, the constant collection of information and memorabilia, which means at the same time sharing memories about DT64 and the media landscape of which it was a part, both of which have long disappeared. In that sense, the Facebook page can be seen as an attempt to stretch DT64's time into the future. This archiving function is, however, as we have tried to show, somewhat limited by the affordances of the platform's promoting new uploads rather than searches through posted materials.

\section{Flow}


Temporality is a central aspect of the experience of Facebook in general and in the ways in which the database as well as the algorithm that governs how information are assembled work. As Taina Bucher (2012) demonstrated, the EdgeRank algorithm is constructed out of three components: affinity, weight, and time decay. The visibility of content in the news feed stream is decided based on the closeness of the relationship between users, the importance of the interaction, and the currency of the post. In this sense, practices of connective memory on the Facebook page have a character of "liveness" and are strongly dependent on the factor of time decay. In general, Facebook users' temporal experience is one of immediacy, ephemerality, "liveness," and flow: to be immersed in an atmosphere and an interface of rapid change and forgetfulness, rather than of remembrance and preservation. Every single post, status update, link and like in a Facebook feed is visible only for a short period of time: for the user, the experience and feel of Facebook is one of rapid change, new stories are continually appearing, pushing old stories out of sight, downwards in the stream (Keightley, 2012).

The flow of Facebook, and of social media in general, is in many ways different from the audiovisual flows (TV, radio) that have been theorized in much previous media research. The most important difference might be the lack of collectivity and of shared experiences. Every single user gets in his or her newsfeed a personalized and individually assembled flow of information and entertainment, which is based on relations, interests, and personal configurations (such as privacy settings). For users who do not regularly click on, like, or share updates from DT64, status-updates from the page will gradually disappear from the flow. For the DT64 moderators, this means that far from all of their followers will see every (if any) updates they make. It might even be the case that a minority of the members of the page actually see their posts and updates. To enhance their reach and penetration, they must abide by some general rules (photos and links are better than just text, for example) and they 
must post content that attracts many likes and clicks. But more crucial to the argument here, this platform affordance works against attempts to use the platform as a tool for collective remembering and storytelling. The structure of the platform makes it difficult to create and to disseminate memories and histories of DT64, and it effectively annihilates narrative forms, a point we will return to below.

Recent developments of the Facebook platform, such as the timeline and the Facebook “A Look Back,” which was launched for the 10th anniversary of the platform in 2014, however, explicitly provide a visualization of the multitude of data and information that the company holds of its users. This creates an interesting dialectic within the technological affordances of the platform, between fluidity, "nowness," "liveness” and change on the one hand, and remembrance, archiving, preservation, and stasis on the other.

It is hardly the case that people go very far backwards in the history of DT64 on the timeline, which is inherently supported by the structure of the platform. Rather, they engage in current posts and discussions that receive visibility in their timelines. In that sense, directness of exchange is crucial and encouraged by the platform. The administrators of the DT64 page share pictures, comments, and YouTube clips regularly in order to sustain the conversation and activity on the page. Our survey indicated that material from the DT64 page was predominantly encountered as posts that appeared along with other posts in the newsfeed of individual users. Users rarely go directly to the page to check for new content. Only strongly engaged content or new users browse through the page, its picture repository and the timeline. This supports the immediacy and directness of engagement that is fostered by the platform following a "stream logic" that potentially opposes continuity.

However, the technological affordances of Facebook create and uphold some continuity, which has been more emphasized with the introduction of the timeline feature that was introduced in December 2011 (Lessin, 2011). The timeline is of particular interest for the 
analysis of the DT64 Facebook page in terms of temporal experiences. It represents, on the one hand, the history of the page and the posts provided by the administrators as well as by the users. It invites users to mark historical milestones of the channel DT64, e.g. the first broadcast, full-time programming, and when DT64 was taken off the air. The calendar aspect embedded in the Facebook page combines immediacy, i.e. a stream of new posts that people engage with, and duration, i.e. users can go back on the timeline and engage with older posts. In this way, the administrators of the page have more opportunities to distinguish and to clarify - for the followers of the page - important points in the history of DT64 and of its Facebook presence. These archiving practices structure the perception of and engagement with the temporal aspects of remembering. In the constant stream of now-ness, reappearing administrator posts, and folders that users can return to in order to construct a partial stability of memories.

\section{Narrative}

There is a fundamental relationship between time and narrative. In the work of Paul Ricoeur (1984), narrative is only meaningful to the extent that it portrays the features of temporal experience, while time only "becomes human time to the extent that it is organized after the manner of a narrative” (p. 3). In general terms, media platforms such as Facebook contribute to the possibility of telling stories and performing memory in different ways, but as noted by Garde-Hansen (2009), for example, the memories performed in such digital domains to a large extent escape the narrative form. There are no beginnings or endings; there are additions and re-combinations of data, in what, according to Garde-Hansen (2009), can be described as the cultural form of the database. The Facebook algorithm, which prioritizes social affinities and newness as well as the limited possibilities for creating meaningful principles for ordering and effectively narrating uploaded material, is in many ways determining the narrative possibilities of the platform. Nevertheless people use the DT64 page 
to tell stories, narrate their own experiences and to connect their personal narrative to a larger story of DT64 and the GDR. Facebook itself stresses the narrative power of the platform through projects such as "Facebook Stories," collecting narratives of how the platform was employed in "extraordinary ways." 6

The very existence of a commemoration page devoted to DT64 bears further witness of the decentralizing possibilities of social media platforms for collective memory. One of our interviewees, who used to be a lay-DJ at DT64, summarizes his experience and ways of engaging with the page as follows:

I just liked the page in order to find people from back then.... But I didn’t. In one of the groups they were really positive towards me. Some - two, maybe - even said that they remembered my voice from my shows with the channel, but well that's it actually. I visit the site from time to time, when they post new topics. Last time, we discussed the means by which we listened to DT64.

However the page itself, due to technological affordances, is highly centralized and hierarchical. The administrators of the page have full control over its content and the structure. Furthermore, the platform design of Facebook does not allow for the followers of the page to become anything other than an audience, mainly reacting to the posts uploaded by the administrators as their posts are the ones that are visible. Most of the users almost never share digitalized memorabilia on the page. Their postings and comments on the page have almost no visibility as they do not show up in the live streams ${ }^{7}$. The administrators, however,

\footnotetext{
${ }^{6}$ https://www.facebookstories.com/, accessed March 10, 2014.

7 The other possible Facebook feature would have been the group feature. The description of Facebook groups reads as follows: "Create a private space. Have things you only want to share with a small group of people? Just create a group, add friends, and start sharing. Once you have your group, you can post updates, poll the group, chat with everyone at once, and more. Share different things with different people. Groups let you share things with the people who will care about them most. By creating a group for each of the important parts of your life — family, teammates, co-workers — you decide who sees what you share.”

(https://www.facebook.com/about/groups, accessed 3 March 2014). This description suggests specific possibilities for restricting access, which would potentially impede the group's general visibility within Facebook. It is thus plausible that the DT64 administrators chose the page feature for these reasons.
} 
regularly call for materials from specific shows aired on DT64. These calls become incentives to digitalize analogue materials and contribute to the common archive on the Facebook pages. In the case of DT64, the administrators' main activity is to repost and promote these user posts. The administrators, then, choose, assemble, and partly edit the objects that become part of the archive as well as determine their visibility. In that sense, they are gatekeepers for the "objects of remembrance" (Price, 2009) that are visible on the page. To what extent is what they do possible to interpret as a form of narration? This privileged position of the administrators is afforded by the infrastructure that the Facebook page as a feature provides, namely the presence and visibility of brand posts on the page and the relative invisibility of user posts that are collected in one field, but that are not exposed in chronological order on the timeline. In the case of DT64, posts by the administrators outweighed the number of user posts considerably during the two weeks analyzed quantitatively here: Only 1.8 per cent of overall engagement were user posts to the page. This dominance was also reflected in the user survey. The 27 survey participants regularly read content, but added posts to the site very rarely. They were, however, using the possibility to engage with administrator posts through likes, shares, and comments.

The DT64-page on Facebook shows the possibility for “ordinary people” to tell their own histories with the aid of social media platforms, but the technical affordances of Facebook simultaneously privilege already-established stories to be retold. A prerogative for the publication format of the platform is briefness and concision; posts have to be rather short in order to appeal to other users, which in turn contributes to DT64's posts remaining visible in the follower's newsfeed.

Another technological pre-supposition is that pictures and links in terms of engagement "work” better than words as status updates. For the moderators of DT64, it is therefore of great importance to find materials to share that will help maintain impact and 
visibility. All posts in the Facebook page during the period we studied included links and/or pictures. It is clear that it mainly is through assembling a vast amount of photographs that the page works as an archive. The photographs uploaded by the moderators of old record covers, for example, of DT64 songbooks ${ }^{8}$ and cassettes with recorded broadcasts, but also more general materials such as photographs from Bruce Springsteen’s famous “Rockin’ the Wall” concert in East Berlin in 1988 and the cover from one of the records released with the official songs of the "Freie Deutsche Jugend" in the $1970 s^{9}$. These technological affordances, the briefness and the privilege given to pictures and links, arguably undermines the possibilities for telling "alternative” stories. The image of DT64 and the (n)ostalgic reproductions of memorabilia from the 1970s and 80s are mainly inscribed in already dominating narratives, as the moderators are mainly using the resources already at hand to fill the page with content (YouTube-clips from the “Rockin’ the Wall” concert, for example), and as they upload pictures of “retro-cool” artefacts from East Germany.

\section{Conclusion}

Media technologies in general and Facebook in particular are part of the current connective media ecology (van Dijck, 2013). They also structure our temporal experiences in fundamental ways. This is expressed in a growing commentary on "the end of temporality" (Crary, 2013; Jameson, 2003) and diagnosis of “hurried lives” (Davis, 2013). The shared tenor is that the character and principles that guide dominant media technologies nowadays, namely the constant flow and newness, have implications for our temporal experiences and production of meaning in general. Mark Andrejevic (2013) emphasized a change towards predictive marketing that "allow[ed] for aggregation without collectivization and for exchange without deliberation” (p. 65). The constant production, collection, and analysis of

\footnotetext{
${ }^{8}$ DT64 published songbooks with the lyrics to popular songs, so that the audience could sing a long at home, in front of the radio set.

${ }^{9}$ The Freie Deutsche Jugend (Free German Youth) was the official communist youth movement of the German Democratic Republic and the Socialist Unity Party of Germany.
} 
data results in the annihilation of interpretation. Platforms foster exchange but not understanding and engagement with actual content. As our analysis shows, the technological affordances of Facebook that are based on the specific business model of the platform contribute to this development and to the fact that exchange value trumps the use value(s) of the platform. The ways in which former DT64 listeners use the Facebook page reflects the platforms economically-motivated focus on immediacy instead of on endurance. For the users of the Facebook page for DT64, this creates tension since the platform effectively restrains their intended memory work and their attempts to use it to write and capture the history of the radio station. This is connected to the three principles we have discussed in the article: archive, flow, and narrative. The weak support for uploading and organizing of DT64 memorabilia (recordings of broadcasts, stickers, flyers) work against the archiving intentions of the page's founders. The fact that the temporal experience of Facebook, the flow, is personalized for every individual user, and the fact that it is impossible for the moderators of the Facebook page to reach all their followers with every post further undermines the possibilities for memory work on Facebook. The personalized flow annihilates the collective and simultaneous experience and meaning production. In comparison to the flow of content in radio and television, the flow in social network media undermines narrative instead of enhancing it. Page owners or moderators become increasingly focused not on narrative (history, memory, and storytelling) but on presence: on constant updates to keep the flow of the page to maintain its visibility for their members (in their newsfeeds). They follow, hence, the inherent principles of the platform and contribute to the increased flow.

While experiences of time remain multilayered for our study participants, social media platforms such as Facebook, which fundamentally rely on the newness principle, only partially represent and offer ways for engaging with this experienced multiplicity. Although 
integrating narrative elements potentially offer different temporalities and glimpses of stability, social network time remains predominantly ephemeral. 


\section{References}

Andrejevic, M. (2013). Infoglut. How too much information is changing the way we think and know. New York, NY: Routledge.

Bergson, H. (1960). Time and free will: An essay on the immediate data of consciousness. New York, NY: Harper \& Row.

Bolter, J.D., MacIntyre, B., Nitsche, M., \& Farley, K. (2012). Liveness, Presence, and Performance in Contemporary Digital Media. In U. Ekman (Ed.), Throughout. Art and Culture Emerging with Ubiquitous Computing (pp. 279-310). Cambridge, MA: MIT Press.

boyd, d. (2012). White flight in the networked publics? How race and class have shaped American teen engagement with MySpace and Facebook. In L. Nakamura \& P. ChowWhite (Eds.) Race after the internet (pp. 203-22). New York, NY: Routledge.

Bucher, T. (2012). Want to be on the top? Algorithmic power and the threat of invisibility on Facebook, New Media \& Society, 14(7), 1164-80.

Buck-Morss, S. (1990), The Dialectics of Seeing. Walter Benjamin and the Arcades Project. Cambridge, MA: MIT Press.

Caers, R., De Feyter, T., De Couck, M., Stough, T., Vigna, C., \& Du Bois, C. (2013).

Facebook: A literature review, New Media \& Society, 15(6), 982-1002.

Cohen, N.S. (2008). The valorization of surveillance: Towards a political economy of Facebook, Democratic Communiqué, 22(1), 5-22.

Crary, J. (2013). 24/7. Late capitalism and the ends of sleep. London: Verso.

Crow, G. \& Heath, S. (2002). Introduction. In G. Crow \& H. Sue (Eds.), Social conceptions of time. structure and process in work and everyday life (pp. 1-8). Basingstoke: Palgrave Macmillan. 
Davis, M. (2013). Hurried lives: Dialectics of time and technology in liquid modernity, Thesis Eleven, 118(1), 7-18.

Dean, J. (2008). Communicative capitalism: Circulation and the foreclosure of politics. In M. Boler (Ed.), Digital media and democracy (pp. 101-21). Cambridge, MA: MIT Press. Elmer, G. (2003). Profiling machines. Mapping the personal information economy. Cambridge, MA: MIT Press.

Facebook (2012). Under the Hood: Scheduling MapReduce jobs more efficiently with Corona. https://www.facebook.com/notes/facebook-engineering/under-the-hood-schedulingmapreduce-jobs-more-efficiently-with-corona/10151142560538920, accessed March 3, 2014.

Fuchs, C. (2014). Digital prosumption labour on social media in the context of the capitalist regime of time, Time \& Society, 23(1), 97-123.

Fuchs, C., \& Sevignani, S. (2013). What is digital labour? What is digital work? What's their difference? And why do these questions matter for understanding social media?, TripleC, 11(2), 237-93.

Garde-Hansen, J. (2009). MyMemories?: Personal digital archive fever and Facebook. In J. Garde-Hansen, A. Hoskins, \& A. Reading (Eds.), Save as... digital memories (pp. 13550). New York, NY: Palgrave Macmillan.

Garde-Hansen, J., Hoskins, A., \& Reading, A. (2009). Introduction. In J. Garde-Hansen, A Hoskins \& A Reading (eds), Save as...digital memories (pp. 1-21), New York, NY: Palgrave Macmillan.

Gerlitz, C. (2012). Acting on data. Temporality and self-evaluation in social media, http://eprints.gold.ac.uk/7076/ accessed March 28, 2014. 
Gershuny, J. (2002). Service regimes and the political economy of time. In G. Crow \& S. Heath (Eds.), Social conceptions of time. structure and process in work and everyday life (pp. 24-37) Basingstoke: Palgrave Macmillan.

Giddens, A. (1994). Beyond left and right. Cambridge: Polity Press.

Gillespie, T. (2010). The politics of 'platforms,' New Media \& Society, 12(3), 347-64.

Harvey, D. (1990). The condition of postmodernity: An enquiry into the origins of cultural change. Oxford: Blackwell.

Hoskins, A. (2009). The mediatisation of memory. In J. Garde-Hansen, A. Hoskins, \& A. Reading (Eds.) Save as...digital memories (pp. 27-43). New York, NY: Palgrave Macmillan.

Hyunjin, K. \& McAllister, M.P. (2011). Selling you and your clicks: Examining the audience commodification of Google, TripleC (Cognition, Communication, Co-Operation): Open Access Journal for a Global Sustainable Information Society, 9(2), 141-53.

Author (2010).

Jameson, F. (2003). The end of temporality, Critical Inquiry, 29(4), 695-718.

Authors (2012).

Keightley, E. (2012). Introduction: Time, media, modernity. In E. Keightley (Ed.), Time, media and modernity, (pp. 1-24). Basingstoke: Palgrave Macmillan.

Keightley, E. (2013). From immediacy to intermediacy: The mediation of lived time, Time \& Society, 22(1), 55-75.

Lagerkvist, A. (2012a). 9.11 in Sweden: commemoration at electronic sites of memory, Television \& New Media, first published on September 14, 2012 doi:10.1177/1527476412457996. 
Lagerkvist, A. (2012b). Recension. [Review] Motti Neiger, Oren Meyers och Eyal Zandberg (red.) On media memory: Collective memory in a new media age, Nordicom Information, 34(1), 73-76.

Lange, P.G. (2007). Publicly private and privately public: Social networking on YouTube, Journal of Computer-Mediated Communication, 13(1), 361-80.

Lefebvre, H. (2004). Rhythmanalysis. London: Continuum.

Leong, S., Mitew, T., Celletti, M., \& Pearson, E. (2009). The question concerning (Internet) time, New Media \& Society, 11(8), 1267-85.

Lessard, B. (2009). Archiving the gaze: Relation-images, adaptation, and digital mnemotechnologies. In J. Garde-Hansen, A. Hoskins, \& A. Reading (Eds.), Save as... digital memories, (pp. 115-34). New York, NY: Palgrave Macmillan.

Lessin, S. (2011). Tell Your Story with Timeline. https://www.facebook.com/notes/facebook/tell-your-story-withtimeline/10150289612087131, accessed March 10, 2014.

Lietz, T., Honeit, R., \& Rauhut, S. (2006). Die Rundfunknutzung Jugendlicher in der DDR [Broadcasting usage of young people in the GDR], in Jahrbuch fur Kommunikationsgeschichte [Yearbook of Communication History] 8, 194-219.

Marwick, A.E. \& boyd, d. (2011). I tweet honestly, I tweet passionately: Twitter users, context collapse, and the imagined audience, New Media \& Society, 13(1),114-33.

Meyrowitz, J. (1985). No sense of place: The impact of electronic media on social behavior, New York, NY: Oxford University Press.

Neiger, M., Meyers, O., \& Zandberg, E. (2011). On media memory: Collective memory in a new media age. London: Palgrave Macmillan. 
Peters, J. (2013). Calender, Clock, Tower. In J. Stolow (ed.) Deus in Machina. Religion, technology and the things in between, (pp. 25-42). New York: Fordham University Press.

Price, M. (2009). Objects of remembrance: A memoire of American opportunities and Viennese dreams. New York, NY: Central European University Press.

Ricoeur, P. (1984). Time and narrative (Vol. 1), Chicago, IL: University of Chicago Press. Rotman, D., \& Preece, J. (2010). The 'WeTube' in YouTube - creating an online community through video sharing, International Journal of Web-based Communities, 6(3), 31733.

Sauter, T. (2013). "What’s on your mind?" Writing on Facebook as a tool for self-formation, New Media \& Society, first published on July 8, 2013 doi:10.1177/1461444813495160.

Scannell, P. (2014). The historicality of central broadcasting institutions. In M. Djerf-Pierre \& M. Ekström (Eds.), A history of Swedish broadcasting. Communicative ethos, genres and institutional change. Gothenburg: Nordicom.

Stahl, H. (2010). Mediascape and Soundscape. Two Landscapes of Modernity in Cold War Berli. In P. Broadbent \& S. Hake (Eds.), Berlin. Divided City, 1945-1989, (pp. 56-65). Oxford: Berghahn Books.

Ulrich, A. \& Wagner, J. (1993). DT64. Das Buch zum Jugendradio 1964-1993. Leipzig: Thom Verlag.

Urry, J. (2002). Time, complexity and the global. In G. Crow \& S. Heath (Eds.) Social Conceptions of time, structure and process in work and everyday life (pp. 11-23). Basingstoke: Palgrave Macmillan.

van Dijck, J. (2007). Mediated memories in the digital age. Palo Alto, CA: Stanford University Press. 
van Dijck, J. (2013). The culture of connectivity. New York: Oxford University Press.

van Dijck, J., \& Poell, T. (2013). Understanding social media logic, Media and Communication, 1(1), 2-24.

Zhao, X., Salehi, N., Naranjit, S., Alwaalan, S., Voida, S., \& Cosley, D. (2013). The many faces of Facebook: Experiencing social media as performance, exhibition, and personal archive, paper presented to Proceedings of the SIGCHI Conference on Human Factors in Computing Systems, Paris, France. 